\title{
Ethnicity predicts perceptions of smoking and smoking cessation among veterans
}

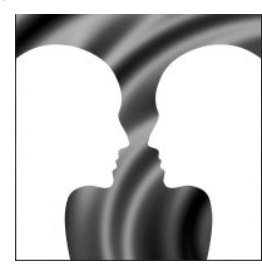

\author{
C.A.KARVONEN-GUTIERREZ ${ }^{1}$ MPH, L.A. EWING ${ }^{1}$ M P , \\ N. J. TAYLOR ${ }^{3,4}$ MS BSN RN, C. A. ESSENMACHER ${ }^{6}$ MSN CNS \& \\ S. A. D UFF Y ${ }^{2,5}$ Ph D R N \\ ${ }^{1}$ Research Health Science Specialist, ${ }^{2}$ Research Investigator, Ann Arbor VA Center for Clinical Management \\ Research, Health Services Research and Development, ${ }^{3}$ Lecturer, University of Michigan School of Nursing, \\ ${ }^{4}$ Cardiology Nurse, University of Michigan Health System, ${ }^{5}$ Associate Professor, Departments of Otolaryngology \\ and Psychiatry, School of Nursing, University of Michigan, Ann Arbor, and ${ }^{6}$ Tobacco Treatment Coordinator, \\ Battle Creek VA Medical Center, Battle Creek, MI, USA
}

Keywords: culture/ethnicity, mental health settings, substance abuse

Correspondence:

S. A. Duffy

Ann Arbor VA Center for Clinical

Management Research

Health Services Research and

Development

and

Departments of Otolaryngology

and Psychiatry

School of Nursing

University of Michigan

2215 Fuller Road

Ann Arbor

MI 48105

USA

E-mail:bump@umich.edu

Accepted for publication: 21 April 2011

doi: 10.1111/j.1365-2850.2011.01757.x

\section{Accessible summary}

- This study shows that, compared with White smokers, non-White smokers treated in a primarily psychiatric Veterans Affairs hospital were more motivated to quit smoking, yet less likely to be interested in traditional cessation interventions such as intensive nurse counselling and medications.

- Novel strategies such as take-home cessation materials, Web-based interventions and peer counselling may be needed to reach non-White veteran smokers.

- These and other strategies will be needed to address the increasing numbers of non-Whites entering the military, especially returning Operation Enduring Freedom/ Operation Iraqi Freedom veterans, many of whom smoke and have co-morbid post-traumatic stress disorder and traumatic head injuries making quitting smoking difficult.

\begin{abstract}
The objective of this study was to determine if race/ethnicity predicts motivation to quit smoking and preferences for cessation services among smokers serviced by a primarily psychiatric Veterans Affairs hospital. A self-administered survey was given to a convenience sample of smokers $(n=146)$ at the Battle Creek Veterans Affairs Medical Center. Univariate, bivariate and multivariate regression analyses were calculated to determine the association between race/ethnicity and motivation to quit smoking. Forty-two per cent of the sample was non-White. Non-White patients smoked significantly less cigarettes per day as compared with White patients $(P=0.002)$. In the multivariate analyses, compared with Whites, non-Whites had 3.5 times greater odds of thinking that quitting smoking was extremely/very important to health $(P=0.01)$, 4.0 times greater odds of thinking of quitting using tobacco products in the next 30 days $(P=0.004)$ and 3.4 times greater odds of being interested in receiving smoking cessation services $(P=0.007)$. Yet, non-White patients were less likely to be interested in intensive nurse counselling and cessation medications. As the number of non-Whites continues to increase in the military, novel strategies may be needed to capitalize on the high motivation to quit smoking and preference for non-traditional interventions among non-White smokers treated in Veterans Affairs hospitals.
\end{abstract}




\section{Introduction}

\section{Smoking and veterans}

Although smoking rates among veterans have decreased from $33 \%$ to $22.2 \%$ in recent years (Office of Quality and Performance 2001, Department of Veterans Affairs VHA, Office of the Assistant Deputy Under Secretary for Health for Policy and Planning 2006), smoking remains a problem in the Veterans Affairs (VA), particularly among those with low socio-economic status and co-morbid psychiatric and substance abuse problems, all of which are known to exacerbate smoking (McKinney et al. 1997). Both smoking rates and psychiatric co-morbidities are higher in the VA compared with non-VA populations (Office of Quality and Performance 2001, Centers for Disease Control and Prevention 2003). In fact, the rate of smoking among psychiatric patients is two to four times higher than the rate in the general population, accounting for $44 \%$ of the total US tobacco market (Prochaska et al. 2004).

\section{Patterns of smoking among African Americans}

Smoking rates among African Americans and Whites are similar $(19.8 \%$ and $21.4 \%$ respectively; Centers for Disease Control and Prevention 2007). Yet, African Americans typically smoke fewer cigarettes per day compared with other racial and ethnic groups and begin smoking later in life (Royce et al. 1993, Li 2008, Whitten 2009). Despite this, African Americans suffer disproportionately from tobacco-related diseases (Allen \& Unger 2007) such as lung cancer (American Cancer Society 2009), cerebrovascular disease (Kung et al. 2008) and cancer (Okuyemi et al. 2001, Chen et al. 2009, Larson et al. 2009).

\section{Smoking cessation behaviours among African Americans}

Regardless of education level, occupation, age and smoking pattern, African Americans are reported to be more motivated to quit smoking than Whites (Boardman et al. 2005, Okuyemi et al. 2007). African Americans have strong concerns about the social and health consequences of smoking, favouring strong tobacco restrictions and believing that smoking is unacceptable (Royce et al. 1993). Seventy per cent of African American smokers want to quit smoking completely and are more likely than White smokers to make serious quit attempts, but are less likely than Whites to ultimately quit $(50.5 \%$ vs. $35.4 \%$ ) (Royce et al. 1993 , Centers for Disease Control and Prevention 1998, Campaign for Tobacco-Free Kids 2010).
One possible explanation for racial/ethnic differences in successful quit attempts is that African American smokers are significantly less likely to report using nicotine replacement therapy for smoking cessation than White smokers (Fu et al. 2008a), which is also true among male veteran smokers in the VA (Fu et al. 2005). In addition, the low cessation rates among African Americans may be a consequence of the higher nicotine levels in menthol cigarettes (Royce et al. 1993) more commonly smoked among African Americans (Allen \& Unger 2007). Hence, menthol cigarettes may be more addictive, which makes quitting smoking more difficult (Fu et al. 2008b).

\section{Conceptual model}

The most frequently used model to guide smoking cessation interventions has been the transtheoretical model. The transtheoretical model is based upon six stages of change: precontemplation, contemplation, preparation, action, maintenance, and termination or relapse (Miller 1999). Those persons thinking of quitting in the next 30 days (preparation stage) are motivated to quit and receptive to cessation services (Prochaska \& DiClemente 1983). While these aforementioned studies show differences between African Americans and Whites in regards to attitudes and behaviours related to smoking, these racial differences in motivation to quit have not been well studied in the VA where there are large numbers of smokers treated in psychiatric facilities. Identifying differences in attitudes and behaviours related to smoking among veterans treated in psychiatric facilities may provide insight as to how to tailor interventions to particular racial/ethnic groups. Hence, the specific aim of this study was to determine if race/ethnicity predicts motivation to quit smoking and preferences for cessation services among smokers serviced by a primarily psychiatric VA hospital.

\section{Methods}

\section{Design}

This cross-sectional survey was conducted with a convenience sample of general inpatient, outpatient and residential veteran smokers $(n=146)$ from a primarily psychiatric VA hospital. Race/ethnicity was the independent variable. Potential control variables included demographic, comorbidity and smoking history variables. Three dependent variables assessed motivation to quit smoking, namely: (1) importance of quitting smoking to health; (2) thinking of quitting in the next 30 days; and (3) interest in cessation services other than those currently provided by the VA. Human studies approval was received from the Ann Arbor VA Healthcare System. 


\section{Setting and sample}

The Battle Creek VA Medical Center (BCVAMC), opened in 1924, is located in south-west Michigan and provides primarily mental health and some primary care services to more than 217000 veterans residing in a 20-county area. There are 104 medical and psychiatric inpatient beds and 103 nursing home care unit beds. Specialized services are offered in the Palliative Care Unit and on the Domiciliary Unit. Substance abuse services are available on the 25-bed residential unit and outpatient services through the Substance Abuse Clinic. The BCVAMC also has a PostTraumatic Stress Disorder Program with residential beds and outpatient services. Veterans cared for through the BCVAMC are assessed for tobacco use upon their first visit and receive tobacco treatment through a variety of services, including group, individual and telephonic sessions (Battle Creek VA Medical Center 2010).

Veterans from the Battle Creek VA $(n=146)$ were included if they: (1) were admitted as inpatients or outpatients to general medical, psychiatric, residential or extended care units; and (2) had used some form of tobacco products within 1 month prior to hospitalization. Veterans were excluded if they: (1) were too ill or impaired to participate; (2) were in terminal stages of illness; or (3) were non-English-speaking. The response rate was $98 \%$ $(147 / 150)$ and one survey was from a non-tobacco user resulting in a sample size of 146 .

\section{Procedures}

During a 2-day period in 2007, research assistants approached patients on their units, in their area of treatment, at their bedside or in the smoking shelter, described the study and gave them the anonymous survey to complete and return immediately or to be retrieved later that day. A $\$ 5.00$ canteen coupon was attached to every survey.

\section{Measures}

Racelethnicity, other demographic and co-morbidity measures

To measure race and ethnicity, we used the US census two-tiered question: (1) a two-category question about Hispanic/Latino origins; and (2) a five-category question about race (White, African American, Asian/Asian Indian/ Pacific Islander, American Indian/Alaska Native or other) (Wallman et al. 2000). For the purposes of this analysis, race/ethnicity was re-coded as White vs. non-White; if patients selected both a White and non-White category, they were classified as non-White. Demographic information on age, marital status (married vs. not married), edu- cation (high school diploma or less vs. some college or more) and employment status (employed vs. not employed) was collected. Self-reported medical co-morbidities were measured using a validated instrument (Mukerji et al. 2007) whereby patients were asked about their medical co-morbid conditions, including cancer, lung disease, heart disease, high blood pressure, stroke, diabetes and arthritis/orthopaedic conditions. The number of medical co-morbidities was categorized as 0 or 1 vs. 2 or more.

\section{Tobacco history and nicotine dependence measures}

The primary measure for smoking was nicotine addiction, assessed using the validated, six-question Fagerström Test for Nicotine Dependence (FTND; Heatherton et al. 1991). Coded on a scale of $0-10$, a score of 6 or more constitutes nicotine addiction, greater difficulty quitting and greater benefit from nicotine replacement therapy (Fagerstrom et al. 1990). Standard questions were asked about smoking history including number of years smoked, types of tobacco products used, number of cigarettes smoked per day and interest in types of cessation services.

\section{Smoking cessation motivation measures}

Three questions were asked to measure motivation to quit using tobacco products. Since beliefs have been related to cessation, patients were asked 'How important do you think quitting smoking is to your health?', which was rated on a 5 -point Likert scale ranging from $1=$ not important to 5 = extremely important. For bivariate and multivariate analyses, responses were grouped into extremely and very important vs. moderately, somewhat and not important. Stage of change was measured by the validated question 'Are you currently seriously thinking of quitting smoking or using other tobacco products in the next: (a) 30 days; (b) 6 months; or (c) not thinking of quitting?' (DiClemente et al. 1991). For bivariate and multivariate analyses, responses were grouped into thinking of quitting in the next 30 days vs. all others. Interest in receiving services was measured by the question 'Would you be interested in smoking cessation services different than those provided in the outpatient clinic? (yes/no).'

\section{Data analysis}

Means and frequencies were conducted for all variables. Bivariate analyses were conducted using $\chi^{2}$, Fisher's exact or Student's $t$-tests to examine race/ethnic differences in motivation to quit or interest in cessation services, as well as to examine differences in demographics, co-morbid conditions, and tobacco history and nicotine dependence by race/ethnicity. Multivariate logistic regression models were used to determine the association between race/ 
ethnicity and the dependent variables, adjusting for those variables identified as potential confounders in the bivariate analyses.

Since all of the respondents did not answer all of the questions, the sample size varied for different results. Those with missing data for a particular question were not included in the analysis. Values for $P<0.05$ are reported. Data analysis for the purposes of this study was conducted using SAS version 9.2 (SAS Institute, Cary, NC, USA).

\section{Results}

\section{Univariate and bivariate analyses}

\section{Demographics}

The description of the sample is shown in Table 1. Overall, $42 \%(n=57)$ of the sample was non-White, of which most $(n=50)$ were African-American. White patients were slightly younger (49 years) compared with non-White patients $(52$ years) $(P<0.05)$. About one in five in both racial/ethnic groups was married and just over half had some college or more. Albeit not significantly different, more Whites $(20 \%)$ were employed than non-Whites $(13 \%)$ and the number of medical co-morbidities was slightly higher among non-Whites.

\section{Tobacco use and history}

Non-White patients had slightly lower nicotine dependence scores (4.9) as compared with White patients (5.6). Both groups had smoked for approximately 28 years. There was a significant, and potentially clinically important, difference in number of cigarettes smoked per day among White patients ( 21 cigarettes/day) as compared with non-White patients (16 cigarettes/day) $(P=0.002)$.

\section{Motivation to quit smoking}

About three-quarters of both groups had tried to quit smoking in the past. Both groups felt that quitting smoking was very or extremely important to their health $(P=0.62)$ (Table 1). More non-Whites $(46 \%)$ than Whites $(24 \%)$ were thinking of quitting in the next 30 days $(P=0.03)$ and non-Whites were more likely to be interested in receiving cessation services from the VA $(P=0.002)$. Interestingly, non-Whites were less likely than Whites to prefer intensive nurse counselling $(P=0.03)$ and medications to quit smoking $(P=0.01)$.

\section{Multivariate analyses}

After reviewing the variables in Table 1, three covariates were chosen for the multivariate analyses: (1) age, because there was a difference among the race/ethnic groups; (2) employment status, because the race/ethnic groups varied somewhat on this variable and it is a measure of socioeconomic status; and (3) number of cigarettes per day, as there was variation in quantity by race/ethnic group. As shown in Table 2, after adjustment for covariates, race/ ethnicity was strongly and consistently statistically significantly related to all of the outcome variables. Non-White patients had 3.5 times greater odds of thinking that quitting smoking was very/extremely important to their health as compared with White patients $(\mathrm{OR}=3.50,95 \% \mathrm{CI}$ $1.31,9.37, P=0.01)$. Furthermore, non-White patients had nearly four times greater odds of thinking of quitting using tobacco products in the next 30 days $(\mathrm{OR}=3.95,95 \% \mathrm{CI}$ $1.56,9.98, P=0.004)$ and more than three times greater odds of being interested in receiving smoking cessation services $(\mathrm{OR}=3.3795 \% \mathrm{CI} 1.40,8.13, P=0.007)$ as compared with White patients.

In the multivariate analyses, younger age was also significantly associated with thinking that quitting smoking was very/extremely important to health. For every additional year of age, patients were $6 \%$ less likely to think that quitting smoking was very/extremely important to health $(\mathrm{OR}=0.94,95 \% \mathrm{CI} 0.90,0.99, P=0.02)$. There were no significant associations of age and thinking of quitting using tobacco products or interest in receipt of smoking cessation services. Furthermore, employment status was not associated with any of the motivation to quit (outcome) variables in the multivariate analyses. There were marginal associations between smoking more cigarettes per day and feeling that quitting smoking was very/extremely important to health $(P=0.09)$ and thinking of quitting use of tobacco products in the next 30 days $(P=0.08)$.

\section{Discussion}

Similar to other studies (Royce et al. 1993, Pederson et al. 2000, Boardman et al. 2005, Okuyemi et al. 2007), the non-Whites in this study showed greater motivation to quit smoking than Whites on all three of the motivation to quit variables including feeling quitting smoking is important to their health, thinking of quitting smoking within the next 30 days and interest in smoking cessation services. Despite their high motivation to quit, African American smokers have more unsuccessful quit attempts than Whites (Royce et al. 1993, Centers for Disease Control and Prevention 1998), perhaps because minorities are less likely than Whites to report receiving cessation interventions including advice from their health care providers, counselling and pharmacotherapy (Houston et al. 2005, Fu et al. 2007, Cokkinides et al. 2008). African Americans are more likely to be lighter smokers and light smokers are less likely to 
Table 1

Baseline demographics, health characteristics, tobacco use and interest in tobacco cessation among 146 patients at the Battle Creek VA Hospital Site by race/ethnicity

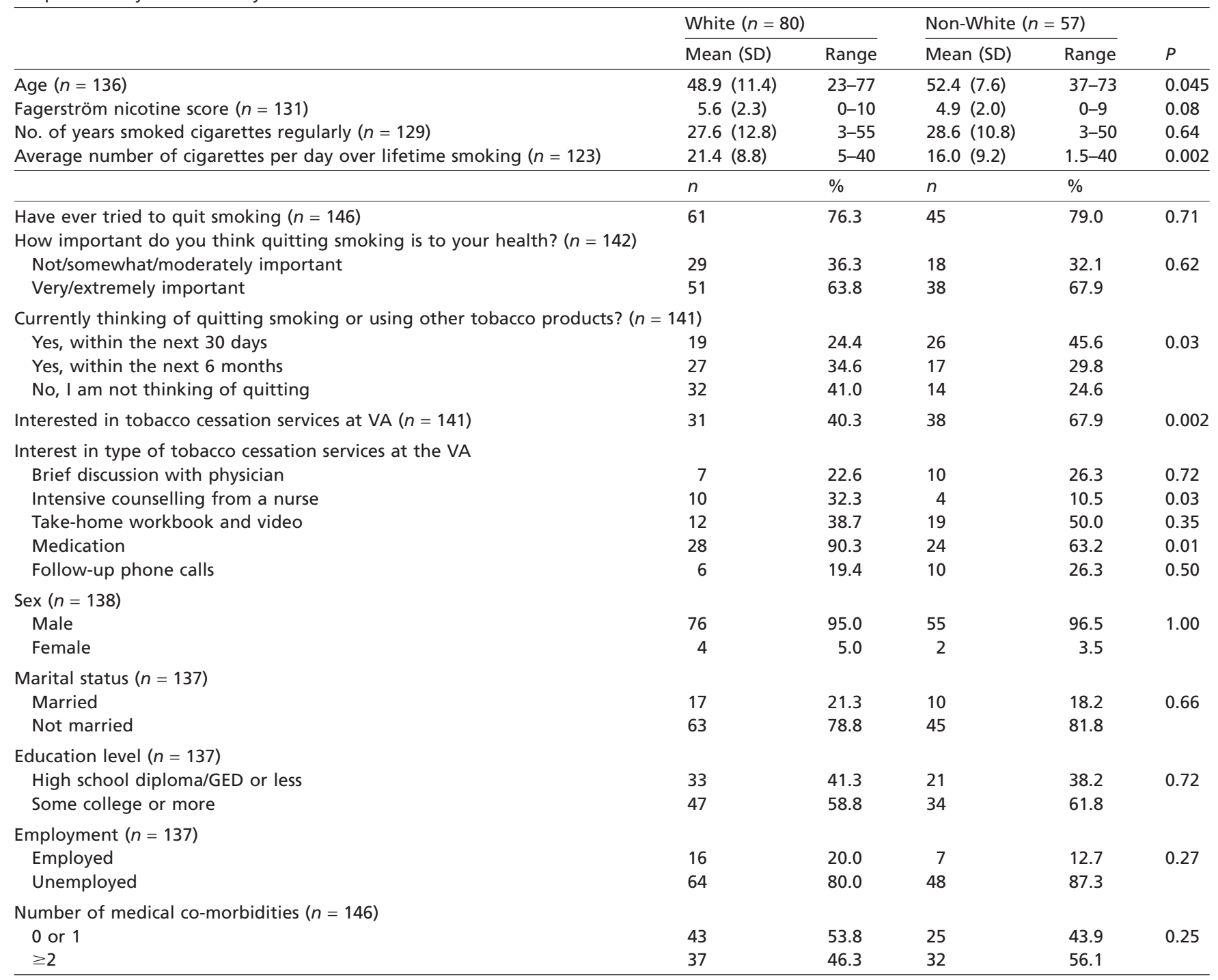

VA, Veterans Affairs; GED, General Educational Development.

Table 2

Multivariate models of race/ethnicity, age, employment status and number of cigarettes per day related to variables measuring motivation to quit smoking variables

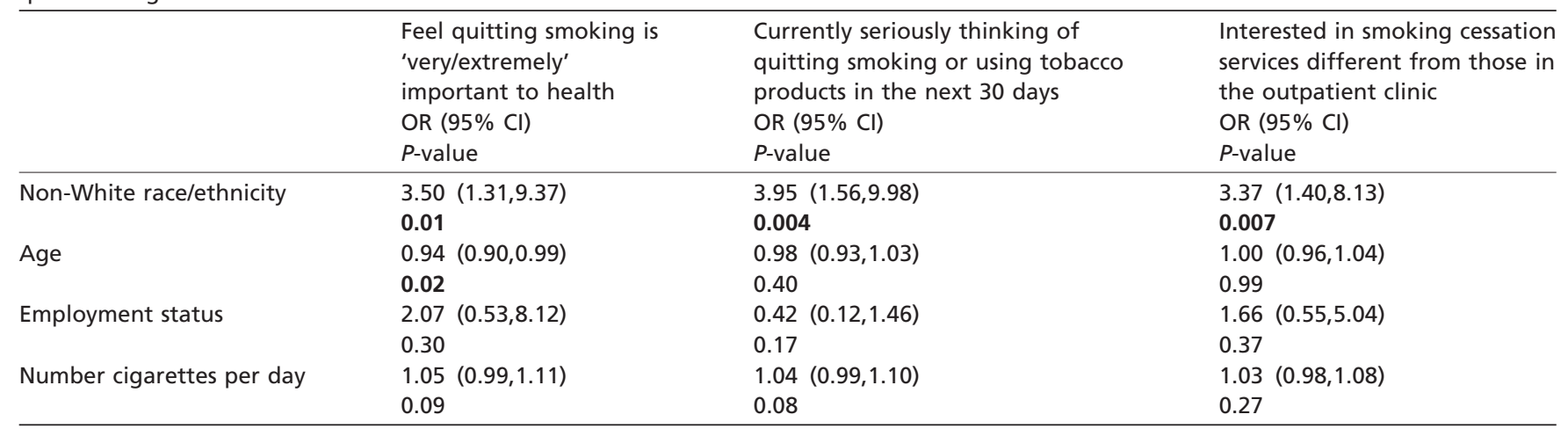

Data in boldface indicate $P<0.05$. 
receive smoking cessation interventions (Okuyemi et al. 2001, Fernander et al. 2008).

Despite being more motivated to quit smoking, nonWhites were less likely than White respondents to be interested in intensive nurse counselling. Negative attitudes and distrust of medical professionals in African American communities is well documented (Fu et al. 2007) and may account for the participants' objection to intensive nurse counselling. Other studies support the notion that African Americans respond more favourably to less intensive counselling such as health education and advice oriented counselling vs. motivational interviewing counselling (Nollen et al. 2006). Albeit not significant, the non-Whites in this study were more likely than Whites to prefer take-home workbooks and videos.

Despite the fact that cessation medications among African Americans greatly increases the probability of quitting (Harris et al. 2004), similar to other studies (Fu et al. 2008b) the non-Whites in this study were less likely to be interested in using cessation medications. Skepticism about the effectiveness and lack of knowledge regarding benefits, and concerns about medication side effects may be some of the reasons why African Americans are less likely to use nicotine replacement therapy (Fu et al. 2007). Moreover, quit smoking advertisements are more likely to be found in White magazines than in non-White magazines (Fu et al. 2007).

As shown in prior studies (Nollen et al. 2006), the nonWhites in this study smoked fewer cigarettes per day, yet had slightly more medical co-morbidities than did Whites perhaps in part because non-Whites were slightly older than Whites. However, prior studies (Okuyemi et al. 2004, Haiman et al. 2006) have shown that despite later initiation of tobacco use and fewer cigarettes smoked per day, there is a disproportionate burden of tobacco-related illnesses among African American tobacco users. While the number of medical co-morbidities did not predict motivation to quit in this study, selected co-morbidities have shown to increase motivation to quit among smokers (Lando et al. 2003, Dominick et al. 2006, Twardella et al. 2006, Duffy et al. 2011). The onset of medical co-morbidities can provide a teachable moment for nurses to initiate cessation services (McBride \& Ostroff 2003).

Unlike other studies (Kiefe et al. 2001), this study showed that socio-economic status, as measured by employment status, did not predict motivation to quit smoking perhaps because socio-economic (employment) status did not vary greatly between non-Whites and Whites. This finding is interesting in that, despite similarities in socio-economic status, race differences in attitudes regarding smoking cessation persisted. Interestingly, younger smokers were more likely to feel that quitting smoking is important to their health, perhaps because they have been exposed to anti-smoking educational campaigns. Hence, older smokers may need increased counselling regarding the negative consequences of smoking.

\section{Implications for mental health clients and mental health nursing practice}

Nursing staff can provide a menu of options for ethnocultural interventions specific to African Americans. Webb et al. (2010) tested an intervention, 'Smoking is Slavery: How Tobacco Hurts Our People', that can be used by nurses which demonstrated an increase in specific risk perceptions, readiness to quit smoking and smoking-related knowledge in a cohort of African American smokers. Intervention materials depicted famous African Americans who died from smoking, and materials exclusively showed African Americans, and emphasized the health consequences and health disparities unique to the population.

Less intensive counselling coupled with self-help materials, such as take-home workbooks, may be more acceptable to non-Whites who prefer to quit on their own. Web-based cessation interventions, which have been shown to be efficacious (Lenert et al. 2003, Pike et al. 2007, Houston \& Ford 2008), may be more popular with younger returning Operation Enduring Freedom/Operation Iraqi Freedom (OEF/OIF) veterans, among whom smoking is especially pronounced (Kirby et al. 2008, Hamlett-Berry et al. 2009). Peer counselling has been shown to be helpful in a variety of settings (Duffy et al. 2010) and may be particularly helpful to non-White smokers who are distrustful of the medical system (Fu et al. 2007).

The type of smoking cessation services that tobacco users were most interested in was medications, and nurses are ideally positioned to work with physicians to facilitate medication orders. Since over half of the patients scored positive for nicotine dependence, nicotine replacement therapy should be considered as it is relatively safe for those with either or both of psychiatric and substance abuse disorders. Bupropion may be particularly helpful for those smokers who have co-morbid depression, but should be used cautiously among smokers with alcohol-related tremors. Varenicline, while efficacious for smoking cessation, should be used extremely cautiously among psychiatric populations due to rare complications of hallucinations, suicidal and aggressive ideations (Morstad et al. 2008, Popkin 2008, Pumariega et al. 2008). Nurses should be trained to understand patients' adherence attitudes and to deliver patient-centred care during medication education and administration as means to improve quit rates with tobacco cessation medications (Bolster \& Manias 2010, Sun et al. 2011). 


\section{Study limitations}

This is a convenience sample and therefore the results are only generalizable to the patients in the study. Since the sample size was small, only a limited number of covariates could be included in the multivariate analyses. Despite these limitations, over half of the participants were nonWhite and the findings showed a clear relationship between ethnicity and motivation to quit smoking and preferences for cessation treatments among veterans treated at a primarily psychiatric VA hospital.

\section{Conclusions}

This study shows that, compared with White smokers, non-White smokers treated in a primarily psychiatric VA hospital were more motivated to quit smoking yet less likely to be interested in traditional cessation interventions such as intensive nurse counselling and medications. Novel strategies such as take-home cessation materials, Webbased interventions and peer counselling may be needed to reach non-White veteran smokers. These and other strategies will be needed to address the increasing numbers of non-Whites entering the military, especially returning $\mathrm{OEF} /$ OIF veterans, many of whom smoke and have co-morbid post-traumatic stress disorder and traumatic head injuries making quitting smoking difficult.

\section{Acknowledgments}

This study was supported by the Department of Veterans Affairs (SDP 06-003, Rapid Response Proposal 07-307). The authors would like to thank the patients that participated in this study.

\section{References}

Allen B. Jr \& Unger J.B. (2007) Sociocultural correlates of menthol cigarette smoking among adult African Americans in Los Angeles. Nicotine \& Tobacco Research 9, 447451.

American Cancer Society (2009) Cancer Facts and Figures for African Americans 2009-2010. American Cancer Society, Atlanta, GA.

Battle Creek VA Medical Center (2010) Available at: http://www.battlecreek.va.gov/about/ (accessed 9 March 2011).

Boardman T., Catley D., Mayo M.S., et al. (2005) Self-efficacy and motivation to quit during participation in a smoking cessation program. International Journal of Behavioral Medicine 12, 266-272.

Bolster D. \& Manias E. (2010) Person-centred interactions between nurses and patients during medication activities in an acute hospital setting: qualitative observation and interview study. International Journal of Nursing Studies 47, 154-165.

Campaign for Tobacco-Free Kids (2010) Tobacco Use Among African Americans. Available at: http://www.tobaccofreekids.org/research/ factsheets/pdf/0006.pdf (accessed 3 March 2011).

Centers for Disease Control and Prevention (1998) Surgeon General's Report. Available at: http:// www.cdc.gov/tobacco/data_statistics/sgr/1998/ highlights/african_americans/ (accessed 3 March 2011).

Centers for Disease Control and Prevention (2003) Cigarette smoking among adults - United States 2001. Morbidity and Mortality Weekly Report 52, 953-956.
Centers for Disease Control and Prevention (2007) Cigarette smoking among adults - United States, 2006. Morbidity and Mortality Weekly Report 56, 1157-1161.

Chen L.M., Li G., Reitzel L.R., et al. (2009) Matched-pair analysis of race or ethnicity in outcomes of head and neck cancer patients receiving similar multidisciplinary care. Cancer Prevention Research 2, 782-791.

Cokkinides V.E., Halpern M.T., Barbeau E.M., et al. (2008) Racial and ethnic disparities in smoking-cessation interventions: analysis of the 2005 National Health Interview Survey. American Journal of Preventive Medicine 34, 404412.

Department of Veterans Affairs VHA, Office of the Assistant Deputy Under Secretary for Health for Policy and Planning (2006) 2005 Survey of Veteran Enrollees' Health and Reliance Upon VA. Healthcare Analysis and Information Group and the Policy Analysis Service within VHA's Office of the Assistant Deputy Under Secretary for Health for Policy and Planning, Washington, DC.

DiClemente C.C., Prochaska J.O., Fairhurst S.K., et al. (1991) The process of smoking cessation: an analysis of precontemplation, contemplation, and preparation stages of change. Journal of Consulting and Clinical Psychology 59, 295304.

Dominick K.L., Golightly Y.M. \& Jackson G.L. (2006) Arthritis prevalence and symptoms among US non-veterans, veterans, and veterans receiving Department of Veterans Affairs Healthcare. Journal of Rheumatology 33, 348354.

Duffy S.A., Karvonen-Gutierrez C.A., Ewing L.A., et al. (2010) Implementation of the Tobacco Tactics program in the Department of Veterans
Affairs. Journal of General Internal Medicine 25, 3-10.

Duffy S.A., Biotti J.K., Karvonen-Gutierrez C.A., et al. (2011) Medical comorbidities increase motivation to quit smoking among veterans being treated by a psychiatric facility. Perspectives in Psychiatric Care 47, 74-83.

Fagerstrom K.O., Heatherton T.F. \& Kozlowski L.T. (1990) Nicotine addiction and its assessment. Ear, Nose, \& Throat Journal 69, 763765.

Fernander A., Schumacher M., Wei X., et al. (2008) Smoking risk and the likelihood of quitting among African-American female light and heavy smokers. Journal of the National Medical Association 100, 1199-1206.

Fu S.S., Sherman S.E., Yano E.M., et al. (2005) Ethnic disparities in the use of nicotine replacement therapy for smoking cessation in an equal access health care system. American Journal of Health Promotion 20, 108-116.

Fu S.S., Burgess D., van Ryn M., et al. (2007) Views on smoking cessation methods in ethnic minority communities: a qualitative investigation. Preventive Medicine 44, 235-240.

$\mathrm{Fu}$ S.S., Burgess D.J., Hatsukami D.K., et al. (2008a) Race and nicotine replacement treatment outcomes among low-income smokers. American Journal of Preventive Medicine 35, S442-S448.

Fu S.S., Kodl M.M., Joseph A.M., et al. (2008b) Racial/ethnic disparities in the use of nicotine replacement therapy and quit ratios in lifetime smokers ages 25 to 44 years. Cancer Epidemiology, Biomarkers of Prevention 17, 16401647.

Haiman C.A., Stram D.O., Wilkens L.R., et al. (2006) Ethnic and racial differences in the smoking-related risk of lung cancer. The 
New England Journal of Medicine 354, 333342.

Hamlett-Berry K., Davison J., Kivlahan D.R., et al (2009) Evidence-based national initiatives to address tobacco use as a public health priority in the Veterans Health Administration. Military Medicine 174, 29-34.

Harris K.J., Okuyemi K.S., Catley D., et al. (2004) Predictors of smoking cessation among AfricanAmericans enrolled in a randomized controlled trial of bupropion. Preventive Medicine 38, 498-502.

Heatherton T.F., Kozlowski L.T., Frecker R.C., et al. (1991) The Fagerstrom Test for Nicotine Dependence: a revision of the Fagerstrom Tolerance Questionnaire. British Journal of Addiction 86, 1119-1127.

Houston T.K. \& Ford D.E. (2008) A tailored Internet-delivered intervention for smoking cessation designed to encourage social support and treatment seeking: usability testing and user tracing. Informatics for Health and Social Care $33,5-19$.

Houston T.K., Scarinci I.C., Person S.D., et al. (2005) Patient smoking cessation advice by health care providers: the role of ethnicity, socioeconomic status, and health. American Journal of Public Health 95, 1056-1061.

Kiefe C.I., Williams O.D., Lewis C.E., et al. (2001) Ten-year changes in smoking among young adults: are racial differences explained by socioeconomic factors in the CARDIA study? American Journal of Public Health 91, 213218.

Kirby A.C., Hertzberg B.P., Collie C.F., et al. (2008) Smoking in help-seeking veterans with PTSD returning from Afghanistan and Iraq. Addictive Behaviors 33, 1448-1453.

Kung H.C., Hoyert D.L., Xu J., et al. (2008) Deaths: final data for 2005. National Vital Statistics Reports 56, 1-120.

Lando H., Hennrikus D., McCarty M., et al. (2003) Predictors of quitting in hospitalized smokers. Nicotine \& Tobacco Research 5, 215222.

Larson C.O., Schlundt D.G., Patel K., et al. (2009) Trends in smoking among African-Americans: a description of Nashville's REACH 2010 initiative. Journal of Community Health 34, 311320.

Lenert L., Munoz R.F., Stoddard J., et al. (2003) Design and pilot evaluation of an internet smoking cessation program. Journal of the American Medical Informatics Association 10, 16-20.

Li M.D. (2008) Identifying susceptibility loci for nicotine dependence: 2008 update based on recent genome-wide linkage analyses. Human Genetics 123, 119-131.

McBride C.M. \& Ostroff J.S. (2003) Teachable moments for promoting smoking cessation: the context of cancer care and survivorship. Cancer Control 10, 325-333.

McKinney W.P., McIntire D.D., Carmody T.J., et al. (1997) Comparing the smoking behavior of veterans and nonveterans. Public Health Reports 112, 212-217; Discussion 218.

Miller C.E. (1999) Stages of change theory and the nicotine-dependent client: direction for decision making in nursing practice. Clinical Nurse Specialist 13, 18-22.

Morstad A.E., Kutscher E.C., Kennedy W.K., et al. (2008) Hypomania with agitation associated with varenicline use in bipolar II disorder. The Annals of Pharmacotherapy 42, 288-289.

Mukerji S.S., Duffy S.A., Fowler K.E., et al. (2007) Comorbidities in head and neck cancer: agreement between self-report and chart review. Otolaryngology - Head and Neck Surgery 136, 536-542.

Nollen N.L., Mayo M.S., Sanderson Cox L., et al. (2006) Predictors of quitting among African American light smokers enrolled in a randomized, placebo-controlled trial. Journal of General Internal Medicine 21, 590-595.

Office of Quality and Performance (2001) Health Behaviors of Veterans in the VHA: Tobacco Use. 1999 Large Health Survey of Enrollees. Veterans Health Administration, Washington, DC.

Okuyemi K.S., Ahluwalia J.S., Richter K.P., et al. (2001) Differences among African American light, moderate, and heavy smokers. Nicotine 6 Tobacco Research 3, 45-50.

Okuyemi K.S., Ahluwalia J.S., Banks R., et al. (2004) Differences in smoking and quitting experiences by levels of smoking among African Americans. Ethnicity of Disease 14, 127133.

Okuyemi K.S., Cox L.S., Nollen N.L., et al. (2007) Baseline characteristics and recruitment strategies in a randomized clinical trial of AfricanAmerican light smokers. American Journal of Health Promotion 21, 183-191.
Pederson L.L., Ahluwalia J.S., Harris K.J., et al. (2000) Smoking cessation among African Americans: what we know and do not know about interventions and self-quitting. Preventive Medicine 31, 23-38.

Pike K.J., Rabius V., McAlister A., et al. (2007) American Cancer Society's QuitLink: randomized trial of Internet assistance. Nicotine \& Tobacco Research 9, 415-420.

Popkin M.K. (2008) Exacerbation of recurrent depression as a result of treatment with varenicline. The American Journal of Psychiatry 165, 774.

Prochaska J.J., Gill P. \& Hall S.M. (2004) Treatment of tobacco use in an inpatient psychiatric setting. Psychiatric Services 55, 1265-1270.

Prochaska J.O. \& DiClemente C.C. (1983) Stages and processes of self-change of smoking: toward an integrative model of change. Journal of Consulting and Clinical Psychology 51, 390-395.

Pumariega A.J., Nelson R. \& Rotenberg L. (2008) Varenicline-induced mixed mood and psychotic episode in a patient with a past history of depression. CNS Spectrums 13, 511-514.

Royce J.M., Hymowitz N., Corbett K., et al. (1993) Smoking cessation factors among African Americans and whites. COMMIT Research Group. American Journal of Public Health 83, 220-226.

Sun G.C., Hsu M.C., Moyle W., et al. (2011) Mediating roles of adherence attitude and patient education on antidepressant use in patients with depression. Perspectives in Psychiatric Care 47, 13-22.

Twardella D., Loew M., Rothenbacher D., et al. (2006) The diagnosis of a smoking-related disease is a prominent trigger for smoking cessation in a retrospective cohort study. Journal of Clinical Epidemiology 59, 82-89.

Wallman K.K., Evinger S. \& Schechter S. (2000) Measuring our nation's diversity: developing a common language for data on race/ethnicity. American Journal of Public Health 90, 17041708.

Webb M.S., Baker E.A. \& de Ybarra D.R. (2010) Effects of culturally specific cessation messages on theoretical antecedents of behavior among low-income African American smokers. Psychology of Addictive Behaviors 24, 333-341.

Whitten L. (2009) Ethnic groups have contrasting genetic risks for nicotine addiction. NIDA Notes 22, 1-7. 